\title{
Soil response around Donghai offshore wind turbine foundation, China
}

1 Kuntan Chang BEng

Postgraduate student, Center for Marine Geotechnical Engineering, Department of Civil Engineering, State Key Laboratory of Ocean Engineering, Shanghai Jiao Tong University, Shanghai, China

2 Dongsheng Jeng MEng, PhD

Professor, Center for Marine Geotechnical Engineering, Department of Civil Engineering, State Key Laboratory of Ocean Engineering, Shanghai Jiao Tong University, Shanghai, China; Griffith School of Engineering, Griffith University Gold Coast Campus, Queensland, Australia; State
Key Laboratory of Hydrology - Water Resources and Hydraulic Engineering, Hohai University, Nanjing, Jiangsu, China

3 Jisheng Zhang MSc, PhD

Professor, State Key Laboratory of Hydrology - Water Resources and Hydraulic Engineering, Hohai University, Nanjing, Jiangsu, China

4 Yu Zhang BEng

Postgraduate student, Center for Marine Geotechnical Engineering, Department of Civil Engineering, State Key Laboratory of Ocean Engineering, Shanghai Jiao Tong University, Shanghai, China
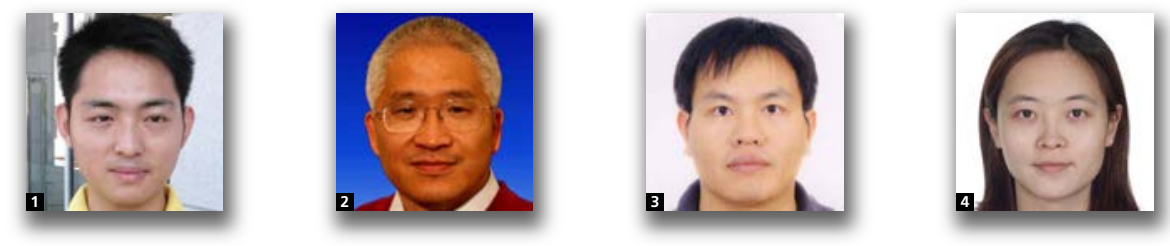

Donghai offshore wind farm next to Shanghai is the first and largest commercial operating offshore wind energy system in China that adopts a high-rising structure foundation. This paper consists of two parts. Details are presented of this wind farm project, site conditions and related engineering solutions in the first part. Then, in the second part, a threedimensional porous model, based on Reynolds-averaged Navier-Stokes equations and Biot's poro-elastic theory, is developed by integrating three-dimensional wave and seabed models to simulate the wave-induced seabed response around the high-rising structure foundation. A parametric study of the effects of the wave and seabed characteristics on the soil response around the wind turbine foundation is conducted. Results concluded from the numerical analysis are as follows: (a) the existence of the structure has a significant effect on the wave transformation and the distribution of wave-induced pore pressure; $(b)$ the magnitude of wave-induced pore pressure increases as wave height or wave period increases. In addition to the current design of the Donghai offshore wind farm with high-rising structure foundation, a gravity-based foundation is also considered and results are compared with those for the high-rising structure foundation.

$\begin{array}{llll}\text { Notation } & & P_{\mathrm{w} 0} & \text { absolute water pressure } \\ A & \text { area of source region } & p_{\mathrm{b}} & \text { hydrostatic pressure in seabed } \\ C & \text { wave phase velocity } & p_{\mathrm{s}} & \text { wave-induced pore pressure in seabed } \\ E_{\mathrm{s}} & \text { Young's modulus } & \left\langle p_{\mathrm{f}}\right\rangle & \text { pressure of fluid } \\ F & \text { function to represent fractional volume of } & S & \text { seabed degree of saturation } \\ & \text { fluid water } & T & \text { wave period } \\ G & \text { shear modulus } & t & \text { time } \\ g_{i} & \text { gravitational acceleration } & u_{\mathrm{s}}, v_{\mathrm{s}}, w_{\mathrm{s}} & \text { soil displacements } \\ H & \text { wave height } & \left\langle u_{\mathrm{f} i}\right\rangle & \text { ensemble mean velocity } \\ h & \text { seabed thickness } & x_{i} & \text { Cartesian coordinate } \\ K_{\mathrm{w}} & \text { true modulus of elasticity of water } & z & \text { soil depth } \\ k & \text { turbulence kinetic energy (TKE) } & \beta & \text { compressibility of pore fluid } \\ k_{\mathrm{s}} & \text { soil permeability } & \gamma_{\mathrm{s}} & \text { unit weight of soil } \\ L & \text { wavelength } & \gamma_{\mathrm{w}} & \text { unit weight of pore water } \\ n_{\mathrm{s}} & \text { soil porosity } & \delta_{i j} & \text { Kronecker delta }\end{array}$




$\begin{array}{ll}\varepsilon_{\mathrm{s}} & \text { volume strain of soil matrix } \\ \mu & \text { dynamic viscosity } \\ \mu_{\mathrm{eff}} & \text { total effective viscosity } \\ \mu_{\mathrm{s}} & \text { Poisson ratio } \\ \mu_{\mathrm{t}} & \text { turbulent viscosity } \\ \rho_{\mathrm{f}} & \text { density of fluid } \\ \sigma_{\mathrm{v} i} & \text { initial stress due to dead loading } \\ \sigma_{x}^{\prime}, \sigma_{y}^{\prime}, \sigma_{z}^{\prime} & \text { effective normal stress } \\ \tau_{x z}, \tau_{x y}, \tau_{y z} & \text { shear stress } \\ \Omega & \text { source region } \\ \omega & \text { wave frequency } \\ \nabla & \text { Laplace operator }\end{array}$

\section{Introduction}

Developments of sustainable energy, especially wind energy, have been rapidly advancing in recent decades. The total wind energy capacity in China had reached $44 \cdot 73$ GW by 2011. However, wind farms in China are onshore, except for the Donghai offshore wind farm (DH-OWF), and $89 \%$ of the wind power capacity is located in Northern China. In fact, the southeast coastal area has rich offshore wind resources, which could provide a good supplement for some coastal cities like Shanghai. According to the offshore development plan drawn up by Chinese coastal provinces, which identified potential projects for inter-tidal (at water depths less than $5 \mathrm{~m}$ ) and offshore (at water depths 5-50 m) developments, Shanghai, Jiangsu, Zhejiang, Shandong and Fujian all hope to have a combined offshore cumulative installed capacity of some 10.1 GW by 2015 and $30 \mathrm{GW}$ by 2020 (Rajgor, 2010).

Moving wind energy offshore makes it possible to use a larger capacity turbine, thus leading to a higher hub and larger rotor, and therefore a larger overturning moment imposed on the foundation. Moreover, the offshore environment is more complex than that onshore. Therefore, it is important to select a suitable foundation style for a specific offshore wind turbine. The gravity-based foundation (GBF) was adopted in the first offshore wind farm in the world, which was installed off the Danish coast in 1991. Mono-piles have been the most popular wind turbine foundation, accounting for over $75 \%$ of existing turbine foundations, in shallow water, owing to its competitive low costs of fabrication and installation (Doherty and Gavin, 2012). A novel offshore wind turbine foundation that is being tested at Fredrikshavn, Denmark, is the suction caisson. With increasing water depth, multiple footing options are used to provide greater moment resistance. Recently a floating platform with tension legs was investigated for deep water. Breton and Moe (2009) described the current status of the development of offshore wind parks in Europe and North America, as well as the option of foundations.
Apart from the aforementioned types of wind turbine foundation, coastal and structural engineers have to provide new options for particular seabed characteristics and marine environments; for instance, a high-rising structure foundation (HRSF) has been used in the DH-OWF.

Marine structures are exposed to marine environmental loading such as wave loadings that are cyclic in nature. Research on responses of offshore foundations to cyclic loads has been conducted over the past few decades, and a series of two-dimensional (2D) or three-dimensional (3D) models have been developed to obtain a better understanding regarding the interaction between soil and pile foundation (Randolph, 1981; Yang and Jeremić, 2002). However, pore water pressures have been left out in the preceding works and the soil was considered as material without voids. In addition, engineers tend to increase pile stiffness or soil ultimate bearing capacity to avoid foundation failure. As a matter of fact, pore water pressure that accumulates in the wave action process may lead to a decrease of effective stress and the eventual collapse of upper structure. Many coastal structures have been damaged by seabed instability in the vicinity of the structure, rather than by design or construction deficiencies (Lundgren et al., 1989). Thus, research on wave-induced pore pressure response around marine structures is meaningful.

Recently, several studies of seabed response in the vicinity of mono-pile foundations have been reported in the literature (Hansen, 2012; Li et al., 2011). It should be pointed out that there is a difference between mono-pile and multi-pile foundations in terms of dynamic behaviour as well as in the way they transfer the applied loads to the surrounding soil (Cuellar, 2011). Therefore, the behaviour of the HRSF - a type of multi-pile foundation, subjected to cyclic load - deserves investigation. Unlike previous works, the present study focuses on the stability of the foundation installed in the DH-OWF and an advanced model is proposed to investigate seabed response under wave loads.

In this paper, both wave and seabed sub-modes, governed by Reynolds-averaged Navier-Stokes (RANS) equations and Biot's consolidation theory (Biot, 1941) respectively, were integrated into one model to investigate the mechanism of seabed response around the HRSF. The Navier-Stokes equation was solved with internal wave generation, as developed for 2D cases by Lin and Liu (1999). A finiteelement method (FEM) model, developed within Comsol Multiphysics, was used to solve the governing equations of the seabed model. Parametric studies were carried out to examine the influence of wave and seabed characteristics on the soil response around the foundation. Furthermore, the seabed liquefaction potential was estimated, then the seabed responses for HRSF and GBF were compared. 


\section{Donghai offshore wind farm}

\subsection{General introduction for Donghai offshore wind farm}

Shanghai, situated in the western Pacific Ocean, is located at the middle portion of the Chinese coast and at the estuary of the Yangtze River. Affected by the East Asian monsoon, the Shanghai region has rich wind resources, the main wind directions being a southeast wind in summer and a northwest or northeast wind in winter. Wind data collected by an anemometer tower installed on the test pile of Donghai Bridge show that at the height of the wind turbine's hub $(90 \mathrm{~m})$, the annual average wind speed reaches $8.6 \mathrm{~m} / \mathrm{s}$, with average effective wind energy $661.7 \mathrm{~W} / \mathrm{m}^{2}$ and accumulated time of annual effective wind power $8248 \mathrm{~h}(3.5 \sim 25 \mathrm{~m} / \mathrm{s})$ (Lu, 2010).

The offshore wind farm project of Shanghai's Donghai Bridge is the first commercial offshore wind farm in China. It is located along a line $1 \mathrm{~km}$ away from either side of Donghai Bridge, with a $1000 \mathrm{t}$ auxiliary channel going through it, as shown in Figure 1 (Ling and Cai, 2012) Its southernmost end is $13 \mathrm{~km}$ from the coastline and the northernmost end is around $6 \mathrm{~km}$ from the coastline. The first phase of DH-OWF, which is

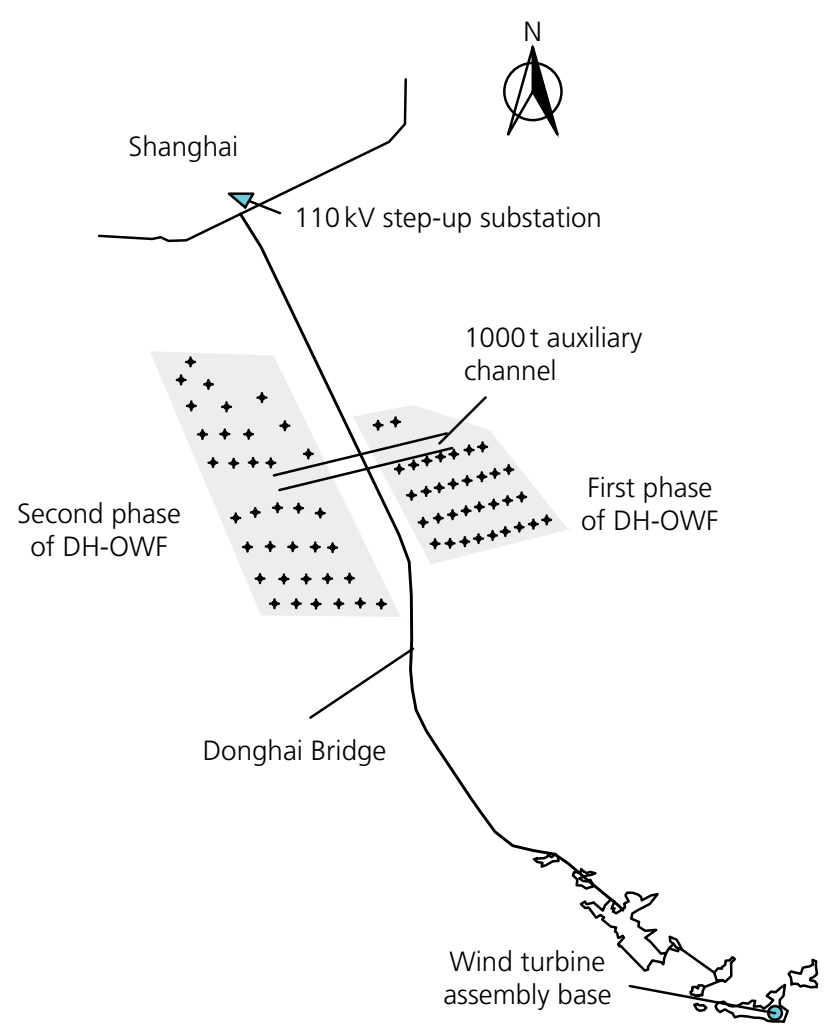

Figure 1. Location of DH-OWF composed of 34 Sinovel ( $3 \mathrm{MW}$ ) turbines, began its construction in April 2008 and became operational in July 2010. The project's total electricity output has been up to $4950 \mathrm{GWh}$ by August 2012 (Liu, 2012). Total project investment is $£ 25.19$ million with total installed capacity $102 \mathrm{MW}$ and the designed annual power generation utilisation hours reach $2624 \mathrm{~h}$, with an expected annual electricity output of 267 GWh. This will meet the annual demand of over 200000 families (Chen, 2011).

According to the environmental impact statement (see http:// www.envir.gov.cn) released by Shanghai Investigation, Design and Research Institute, the second phase of DH-OWF will be located on the west side of the Donghai Bridge with 27 turbines (3.6 MW). In addition, 3.6 MW and $5 \mathrm{MW}$ prototype turbines were installed in 2011 to accumulate experience for further development. Its total installed capacity will be up to $102 \cdot 2 \mathrm{MW}$ when the project is completed in 2014.

\subsection{Characteristics of DH-OWF and its engineering solutions}

Donghai offshore wind farm is different from many offshore wind farms elsewhere in the world because of the following characteristics.

(a) The surface soil of the seabed is silt or a silt quality soil layer that is up to $20 \mathrm{~m}$ thick. Compared with that of wind farms in Europe which is mainly $10 \mathrm{~m}$ of fine sand soil layer (Carter, 2007), the geological situation is quite unfavourable. It was reported that the $4 \mathrm{~m}$ diameter mono-pile foundation can be adopted elsewhere in the world, whereas a $7 \mathrm{~m}$ diameter mono-pile foundation is needed in China (Wang et al., 2009).

(b) It is not uncommon for typhoons to hit southern and eastern provinces of China. At least three typhoons have reached landfall directly in the Shanghai region since 1949. Typhoon Haikui slammed Shanghai in August 2012 and monitoring data acquired from the DH-OWF site show that the maximum instantaneous wind speed reached over $40 \mathrm{~m} / \mathrm{s}$ (Liu, 2012). Therefore, the typhoon risk must be taken into consideration when developing any offshore wind farm project in China.

(c) As illustrated in Figure 1, an auxiliary channel lies in the middle of the turbines, and the minimum distance between turbines and channel is only $30 \mathrm{~m}$. This means that collision with ships represents a potential danger for turbines in DH-OWF. Therefore, it is critical to protect these turbines against such ship impacts.

(d) Although China has built a few pilot demonstration offshore wind farm projects, the key technologies related to turbine manufacture, construction, fabrication and installation are not yet mature. For example, owing to the 
Soil response around Donghai

offshore wind turbine

foundation, China

Chang, Jeng, Zhang and Zhang difficulty of the construction technique in China and the seabed characteristics in the region, the DH-OWF used HRSF, rather than one of the more common offshore wind energy structures used in Europe.

The features of the DH-OWF project described above are severely challenging to the Chinese offshore wind farm industry. Designers and engineers have come up with a series of solutions to reduce the impacts of these disadvantages.

(a) A novel foundation style termed the HRSF (as defined earlier) is proposed, which consists of eight pile-foundations and a mini-platform in the first phase design. The finished structure and sketch model of the HRSF can be seen in Figures 2 and 3 respectively, and more detail will be given in the next section. It is evident that only a mono-pile with a considerably large diameter can be driven in silt soil steadily. The silt soil layer and immature pile driving technique were the main determining reasons why the HRSF was designed to consist of eight piles, each with a diameter of $1.7 \mathrm{~m}$, instead of using a mono-pile with larger diameter.

(b) To protect wind turbines from collision with ships, devices such as steel pipe should be installed around the wind turbine. However, this method may be expensive if all of the turbines are designed with this protection. In the DH-OWF project, engineers designed a reinforced concrete platform at water level that combined the supporting structure with the anti-collision device, as illustrated in Figure 2. This design not only allows the platform to dissipate collision energy, but also to transfer energy to the pile foundation and seabed.

(c) Technical issues have also put constraints on turbine installation. The method adopted at DH-OWF was to

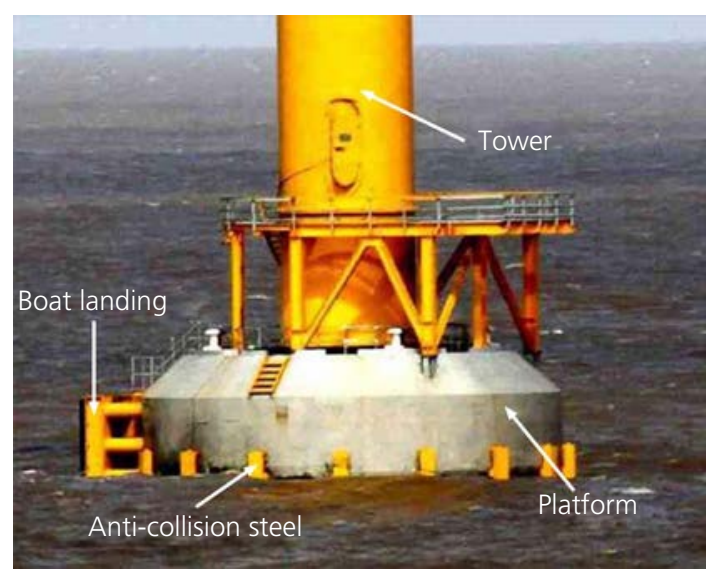

Figure 2. The HRSF in DH-OWF (revised from Lu (2010)) assemble the wind turbine on an assembly base, as shown in Figure 1, in advance; then the whole assembled wind turbine is transported and lifted into position, which is a reliable but costly means of installation.

(d) The potential impact of a typhoon has been taken into consideration when designing wind turbines in DH-OWF. The 'typhoon-resistant' wind turbine will feather its blades (reduce their angle to the wind) and stop when average wind speed exceeds $25 \mathrm{~m} / \mathrm{s}$ or instantaneous wind speed exceeds $36 \mathrm{~m} / \mathrm{s}$.

\subsection{Foundation of Donghai offshore wind farm}

In the first phase of DH-OWF project, the HRSF consists of eight pile-foundations and a mini-platform, as shown in Figure 3. The mini-platform of the HRSF is made up of a $1.5 \mathrm{~m}$ high frustum and a $3 \mathrm{~m}$ high cylinder at the bottom. The base diameter and cut diameter of the frustum are $14 \mathrm{~m}$ and $11 \mathrm{~m}$ respectively. Eight 80 -m-long piles embedded in the seabed at circa $65 \mathrm{~m}$ are arranged equally spaced around a circle of radius $5 \mathrm{~m}$. The steel piles are driven into the seabed with a $5 \cdot 5: 1$ slope and connected to the upper platform by pouring concrete. For the second phase of the DH-OWF project, the design of the HRSF was further adapted with different dimensions and number of piles, as presented in Table 1. Since this design is being trialled for the first time in the world, no research information on foundation stability of the whole wind turbine system could be obtained in the literature.

\section{Theoretical models}

In this study, the phenomenon of wave-seabed interactions in the vicinity of an HRSF, as depicted in Figure 3, is considered. The origin of the Cartesian coordinate is located at the intersection of the centreline of the HRSF and the seabed surface, labelled A. A wave-maker is situated two times the wavelength away from the structure and each end of the computational domain adopts a sponge layer. The foundation structure is modelled from the HRSF of $3 \mathrm{MW}$ turbines with the same scale. Dimensions of the foundation are given in Table 1. In this section, the governing equations for both wave and seabed models will be outlined first, followed by the boundary conditions and numerical scheme.

\subsection{Wave model}

Based on conservation of mass and momentum, the incompressible fluid motion due to a wave can be described by the RANS equations. The following governing equations are expressed in the Einstein summation convention.

1. $\frac{\partial\left\langle u_{\mathrm{fi}}\right\rangle}{\partial x_{i}}=0$ 


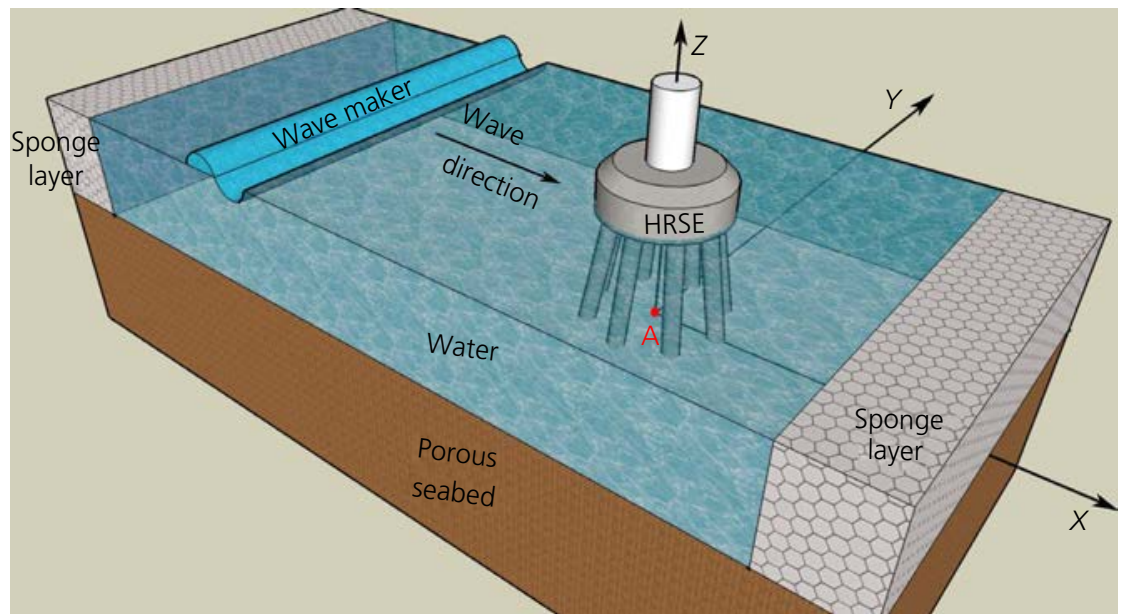

Figure 3. Definition of wave-seabed interactions in the vicinity of HRSF

$$
\frac{\partial \rho_{\mathrm{f}}\left\langle u_{\mathrm{f} i}\right\rangle}{\partial t}+\frac{\partial \rho_{\mathrm{f}}\left\langle u_{\mathrm{f} i}\right\rangle\left\langle u_{\mathrm{f} j}\right\rangle}{\partial x_{j}}=-\frac{\partial\left\langle p_{\mathrm{f}}\right\rangle}{\partial x_{i}}+
$$

2. $\frac{\partial}{\partial x_{j}}\left[\mu\left(\frac{\partial\left\langle u_{\mathrm{f} i}\right\rangle}{\partial x_{j}}+\frac{\partial\left\langle u_{\mathrm{f} j}\right\rangle}{\partial x_{i}}\right)\right]+$

$$
\frac{\partial\left(-\rho_{\mathrm{f}}\left\langle u_{\mathrm{f} i}^{\prime} u_{\mathrm{f} j}^{\prime}\right\rangle\right)}{\partial x_{j}}+\rho_{\mathrm{f}} \boldsymbol{g}_{i}
$$

where $x_{i}$ is the Cartesian coordinate, $\rho_{\mathrm{f}}$ is the density of fluid, $\left\langle u_{\mathrm{f} i}\right\rangle$ is the ensemble mean velocity, $\left\langle p_{\mathrm{f}}\right\rangle$ is the pressure of fluid, $\mu$ is the dynamic viscosity and $\boldsymbol{g}_{i}$ is the gravitational acceleration. The Reynold stress term $\rho_{\mathrm{f}}\left\langle u_{\mathrm{f} i}^{\prime} u_{\mathrm{f} j}^{\prime}\right\rangle$ is modelled by the $k-\varepsilon$ turbulence model (Rodi, 1993).

By applying the eddy-viscosity assumption, the Reynolds stress term can be estimated by

3. $-\rho_{\mathrm{f}}\left\langle u_{\mathrm{f} i}^{\prime} u_{\mathrm{f} j}^{\prime}\right\rangle=\mu_{\mathrm{t}}\left[\frac{\partial\left\langle u_{\mathrm{f} i}\right\rangle}{\partial x_{j}}+\frac{\partial\left\langle u_{\mathrm{f} j}\right\rangle}{\partial x_{i}}\right]-\frac{2}{3} \rho_{\mathrm{f}} \delta_{i j} k$

where $\mu_{\mathrm{t}}$ is the turbulent viscosity, $k$ is the turbulence kinetic energy (TKE) and $\delta_{i j}$ is the Kronecker delta.
Based on Equation 3, Equation 2 can be rewritten as

$$
\begin{aligned}
& \frac{\partial \rho_{\mathrm{f}}\left\langle u_{\mathrm{f} i}\right\rangle}{\partial t}+\frac{\partial \rho_{\mathrm{f}}\left\langle u_{\mathrm{f} i}\right\rangle\left\langle u_{\mathrm{f} j}\right\rangle}{\partial x_{j}}= \\
& -\frac{\partial\left\langle p_{\mathrm{f}}+\frac{2}{3} \rho_{\mathrm{f}} k\right\rangle}{\partial x_{i}}+ \\
& \frac{\partial}{\partial x_{j}}\left[\mu_{\mathrm{eff}}\left(\frac{\partial\left\langle u_{\mathrm{f} i}\right\rangle}{\partial x_{j}}+\frac{\partial\left\langle u_{\mathrm{f} j}\right\rangle}{\partial x_{i}}\right)\right]+\rho_{\mathrm{f}} g_{i}
\end{aligned}
$$$$
\text { 4. }-\frac{\partial\left\langle p_{\mathrm{f}}+\frac{2}{3} \rho_{\mathrm{f}} k\right\rangle}{\partial x_{i}}+
$$

in which $\mu_{\mathrm{eff}}=\mu+\mu_{\mathrm{t}}$ is the total effective viscosity.

The internal wave-maker method developed by Lin and Liu (1999) is used in the present study. In the source region $(\Omega)$, a source function $S\left(x_{i}, t\right)$ is added into the mass conservation, Equation 1, that is

5. $\frac{\partial\left\langle u_{i}\right\rangle}{\partial x_{i}}=S\left(x_{i}, t\right) \quad$ in $\Omega$

\begin{tabular}{|c|c|c|c|c|c|}
\hline & \multirow{2}{*}{ Turbine: MW } & \multicolumn{2}{|c|}{ Pile } & \multicolumn{2}{|c|}{ Platform } \\
\hline & & Number & Diameter: m & Diameter: m & Height: m \\
\hline First phase & $3 \cdot 0$ & 8 & $1 \cdot 7$ & 14 & $4 \cdot 5$ \\
\hline \multirow[t]{2}{*}{ Second phase } & $3 \cdot 6$ & 6 & $2 \cdot 0$ & 14 & $4 \cdot 5$ \\
\hline & $5 \cdot 0$ & 10 & $1 \cdot 7$ & 18 & $4 \cdot 5$ \\
\hline
\end{tabular}

where $S\left(x_{i}, t\right) \neq 0$ within the source region. The value of $S\left(x_{i}, t\right)$ depends on wave characteristics, for example, for a linear monochromatic wave, it is

Table 1. Dimension parameters of HRSF 
6. $S(x, t)=\frac{C H}{A} \sin (\omega t)$

in which $C$ is the wave phase velocity, $H$ is wave height, $A$ is the area of the source region and $\omega$ is the wave frequency.

\subsection{Seabed model}

In this study, we consider an isotropic, homogeneous seabed with the same permeability $\left(k_{\mathrm{s}}\right)$ in all directions. The conservation of mass leads to

7. $\quad \nabla^{2} p_{\mathrm{s}}-\frac{\gamma_{\mathrm{w}} n_{\mathrm{s}} \beta_{\mathrm{s}}}{k_{\mathrm{s}}} \frac{\partial p_{\mathrm{s}}}{\partial t}=-\frac{\gamma_{\mathrm{w}}}{k_{\mathrm{s}}} \frac{\partial \varepsilon_{\mathrm{s}}}{\partial t}$

where $\nabla$ is the Laplace operator; $\gamma_{\mathrm{w}}$ is the unit weight of pore water; $n_{\mathrm{s}}$ is soil porosity; and the volume strain of soil matrix $\left(\varepsilon_{\mathrm{s}}\right)$ and the compressibility of pore fluid $(\beta)$ are defined as

8. $\varepsilon_{\mathrm{s}}=\frac{\partial u_{\mathrm{s}}}{\partial x}+\frac{\partial v_{\mathrm{s}}}{\partial y}+\frac{\partial w_{\mathrm{s}}}{\partial z}$

9. $\quad \beta_{\mathrm{s}}=\frac{1}{K_{\mathrm{w}}}+\frac{1-S}{P_{\mathrm{w} 0}}$

in which $\left(u_{\mathrm{s}}, v_{\mathrm{s}}, w_{\mathrm{s}}\right)$ are soil displacements, $K_{\mathrm{W}}$ is the true modulus of elasticity of water (taken as $2 \times 10^{9} \mathrm{~N} / \mathrm{m}^{2}$ ), $P_{\mathrm{w} 0}$ is the absolute water pressure and $S$ is the degree of saturation.

10a. $\frac{\partial{\sigma_{x}^{\prime}}_{x}}{\partial x}+\frac{\partial \tau_{x y}}{\partial y}+\frac{\partial \tau_{x z}}{\partial z}=-\frac{\partial p_{\mathrm{s}}}{\partial x}$

10b. $\frac{\partial \tau_{x y}}{\partial x}+\frac{\partial \sigma_{y}^{\prime}}{\partial y}+\frac{\partial \tau_{y z}}{\partial z}=-\frac{\partial p_{\mathrm{s}}}{\partial y}$

10c. $\frac{\partial \tau_{x z}}{\partial x}+\frac{\partial \tau_{y z}}{\partial y}+\frac{\partial \sigma_{z}^{\prime}}{\partial z}=-\frac{\partial p_{\mathrm{s}}}{\partial z}$

in which $\left(\sigma_{x}^{\prime}, \sigma_{y}^{\prime}, \sigma_{z}^{\prime}\right)$ are the effective normal stress; and $\left(\tau_{x z}\right.$, $\left.\tau_{x y}, \tau_{y z}\right)$ are shear stress.

In this study, a poro-elastic constitutional model is used to describe the soil behavior in the seabed. Then, effective normal stresses and shear stresses can be expressed in terms of soil displacements as

11a. $\sigma_{x}^{\prime}=2 G\left[\frac{\partial u_{\mathrm{s}}}{\partial x}+\frac{\mu \varepsilon_{\mathrm{s}}}{1-2 \mu}\right], \sigma^{\prime}{ }_{y}=2 G\left[\frac{\partial v_{\mathrm{s}}}{\partial y}+\frac{\mu \varepsilon_{\mathrm{s}}}{1-2 \mu}\right]$ 11b. $\sigma_{z}^{\prime}=2 G\left[\frac{\partial w_{\mathrm{s}}}{\partial z}+\frac{\mu \varepsilon_{\mathrm{s}}}{1-2 \mu}\right], \tau_{x z}=G\left[\frac{\partial u_{\mathrm{s}}}{\partial z}+\frac{\partial w_{\mathrm{s}}}{\partial x}\right]$

11c. $\tau_{x y}=G\left[\frac{\partial u_{\mathrm{s}}}{\partial y}+\frac{\partial v_{\mathrm{s}}}{\partial x}\right], \tau_{y z}=G\left[\frac{\partial v_{\mathrm{s}}}{\partial z}+\frac{\partial w_{\mathrm{s}}}{\partial y}\right]$

where the shear modulus $G$ is related to Young's modulus $E_{\mathrm{s}}$ and the Poisson ratio $\mu_{\mathrm{s}}$ in the form of $E_{\mathrm{s}} / 2\left(1+\mu_{\mathrm{s}}\right)$. It is noted that a positive sign is taken for a compressive normal stress in this study.

Substituting Equation 11 into Equation 10, the conservation of momentum in the $x$-, $y$ - and $z$-directions, respectively, becomes

12a. $G \nabla^{2} u_{\mathrm{s}}+\frac{G}{\left(1-2 \mu_{\mathrm{s}}\right)} \frac{\partial \varepsilon_{\mathrm{s}}}{\partial x}=-\frac{\partial p_{\mathrm{s}}}{\partial x}$

12b. $G \nabla^{2} v_{\mathrm{s}}+\frac{G}{\left(1-2 \mu_{\mathrm{s}}\right)} \frac{\partial \varepsilon_{\mathrm{s}}}{\partial y}=-\frac{\partial p_{\mathrm{s}}}{\partial y}$

12c. $G \nabla^{2} w_{\mathrm{s}}+\frac{G}{\left(1-2 \mu_{\mathrm{s}}\right)} \frac{\partial \varepsilon_{\mathrm{s}}}{\partial z}=-\frac{\partial p_{\mathrm{s}}}{\partial z}$

\subsection{Boundary conditions}

To solve the RANS governing equations, appropriate boundary conditions are required. A sponge layer damping method is applied for vertical velocity component at both domain ends to avoid reflection of waves and interference on current inlet/outlet. At the air-water interface, zero surface tension with $\partial k / \partial \vec{n}=\partial \varepsilon / \partial \vec{n}=0$ is imposed. At the solid surface, a no-slip boundary is given and the turbulence properties are estimated from the standard wall function. To obtain computational stability, the time interval $(\Delta t)$ is automatically adjusted at each time step to satisfy the Courant-Friedrichs-Lewy condition and the diffusive limit condition (Lin and Liu, 1999).

The evaluation of the wave-induced seabed response also requires appropriate boundary conditions. At the seabed surface, the pore pressures $\left(p_{\mathrm{s}}\right)$ and shear stresses $\left(\tau_{x z}, \tau_{x y}\right.$, $\tau_{y z}$ ) equal the wave pressures and shear stresses obtained from the RANS model (wave mode). The bottom of the porous seabed with finite thickness $(h)$ is treated as impermeable and rigid; therefore, zero displacement and no vertical flow occur in this bottom boundary $\left(u_{\mathrm{s}}=v_{\mathrm{s}}=w_{\mathrm{s}}=\partial p_{\mathrm{s}} / \partial z=0\right)$. Zero displacement and gradient of pore pressure are adopted in the four vertical sides far away from the concerned region, 
$u_{\mathrm{s}}=v_{\mathrm{s}}=w_{\mathrm{s}}=\partial p_{\mathrm{s}} / \partial x=0$. The interface between piles and seabed is considered as impermeable and adopts a Neumann boundary condition.

\subsection{Numerical scheme}

The RANS governing equations are solved by a two-step projection method with finite-volume discretisation (Bussmann et al., 2002). The computational domain is divided into a set of structured/unstructured meshes, in which all the fluid properties, such as pressure and velocities, are defined at the cell centroids. The least-square linear reconstruction (LSLR) method (Barth, 1992) is adopted to convert cell centroid data to face centroids to evaluate the quantity gradient at cell centroid. The time derivative is discretised by the forward time difference method. The volume of fluid (VOF) method developed by Hirt and Nichols (1981) is used to track the free water surface. The idea of VOF is to define a function $F$ to represent the fractional volume of fluid water. $F=1$ indicates that the cell is full of water, whereas $F=0$ corresponds to a cell fully occupied by air cells with value of $0<F<1$ containing a water free surface, and the piecewise linear interface calculation (PLIC) method (Rider and Kothe, 1998) is used to reconstruct the air-water interface.

To solve the Biot's consolidation theory outlined previously, a numerical code was developed within Comsol Multiphysics environments. Comsol is a commercial FEM tool that allows the users to design their own governing equations and boundary conditions for specific physical problems. In this study, based on the existing Poro-WSSI II (porous models for wave-seabed-structure interactions, Version II) developed by Jeng's research group (Jeng, 2013), a new Comsol model was developed for 3D porous flow. The outputs of the 3D wave model are integrated into the newly developed Comsol model by the boundary conditions at the interface between water and seabed.

\section{Results and discussion}

The aim of this study is to investigate the wave-induced pore pressure around the HRSF. The parameters used in this study are as close as possible to the situation in the DH-OWF. In this section, a parametric study is carried out to examine the effects of wave and seabed characteristics on soil response around the foundation. The input data for the parametric study are provided in Table 2. All the numerical results given here are from the fifth wave period at which a fully dynamic interaction between wave and foundation structure on porous seabed is achieved.

\subsection{Wave-induced pore pressure around HRSF}

In this section, the wave-induced pore pressure around the HRSF at different times will be examined. Wave parameters and soil characteristics are considered as follows: wave period

\begin{tabular}{lcl} 
Parameter & Value & Unit \\
\hline Wave period, $T$ & $10,7 \cdot 76,5$ & $\mathrm{~s}$ \\
Wave height, $H$ & $2 \cdot 0,1 \cdot 5,1 \cdot 0$ & $\mathrm{~m}$ \\
Water depth, $d$ & $13 \cdot 0$ & $\mathrm{~m}$ \\
Seabed thickness, $h$ & 80 & $\mathrm{~m}$ \\
Permeability, $k_{\mathrm{s}}$ & $10^{-4}$ & $\mathrm{~m} / \mathrm{s}$ \\
Degree of saturation, $S$ & $0.99,0 \cdot 98,0.97$ & - \\
Soil porosity, $n_{\mathrm{s}}$ & $0 \cdot 3$ & - \\
Poisson ratio, $\mu_{\mathrm{s}}$ & $0 \cdot 4$ & - \\
Shear modulus, $G$ & $10^{7}$ & $\mathrm{~N} / \mathrm{m}^{2}$
\end{tabular}

Table 2. Input data of numerical examples

$T=5 \mathrm{~s}$, wave height $H=2 \mathrm{~m}$, soil permeability and degree of saturation are $10^{-4} \mathrm{~m} / \mathrm{s}$ and $0 \cdot 98$, respectively. Figure 4 shows the water surface and wave-induced pore pressure distribution at $1 \mathrm{~m}$ below the seabed surface during a full period $\left(t / T=5 \frac{3}{8}\right.$ to $\left.6 \frac{1}{4}\right)$, which is divided into eight roughly equal parts. It can be seen in the figure that pore pressure is positive on the spots of the wave crest and negative on the wave trough.

The wave-induced pore pressures at different time steps are illustrated in Figure 4. The existence of a structure has significant effects on the distribution of pore pressures, especially in the direction perpendicular to wave propagation and an increase of pore pressure around the foundation is observed. In detail, at the sides of the structure, maximum (or minimum) pore pressure is distributed in regions which are away from the centreline of wave propagation; by contrast, maximum (or minimum) pore pressure is concentrated in the HRSF at the inside of the structure. This is because the existence of the structure partly blocks the cross-sectional space through which the wave flow passes, leading to a larger wave height in front of the structure. After passing the foundation, the wave decays clearly as part of the incident wave energy has been dissipated owing to the wave-structure interaction, as shown in the profile of wave transformation in Figure 4.

Figure 5 illustrates the vertical distributions of the waveinduced pore pressure at point A (referring to Figure 3) during the same full period. As presented in the figure, the maximum magnitude of pore pressure in the wave crest is roughly equal to the absolute value of minimum magnitude in the trough. Moreover, the profiles of pore pressure in the seabed are similar between wave crests and wave troughs. On the one hand, positive wave pressures are imposed on the seabed surface from $t / T=5 \frac{3}{8}$ to $5 \frac{3}{4}$, and the pore pressure attenuates very rapidly within $1.4 \mathrm{~m}$, where a minimum value is reached. Then, a slight increase in magnitude with depth is observed, 


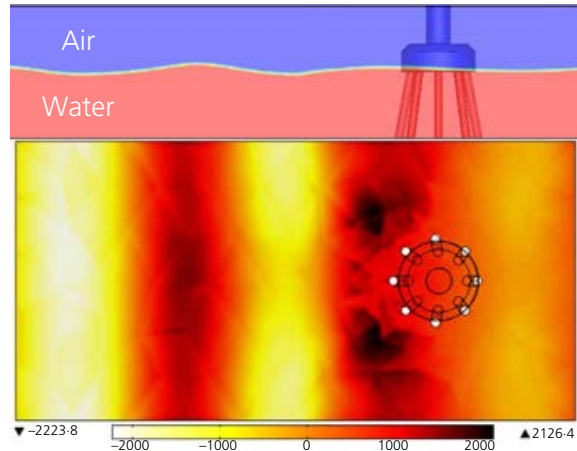

(a)
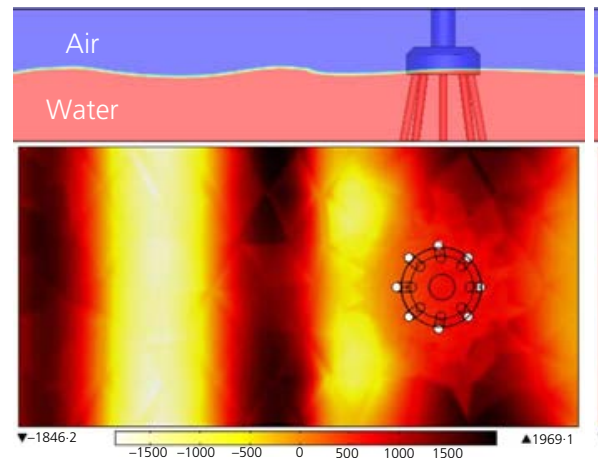

(d)

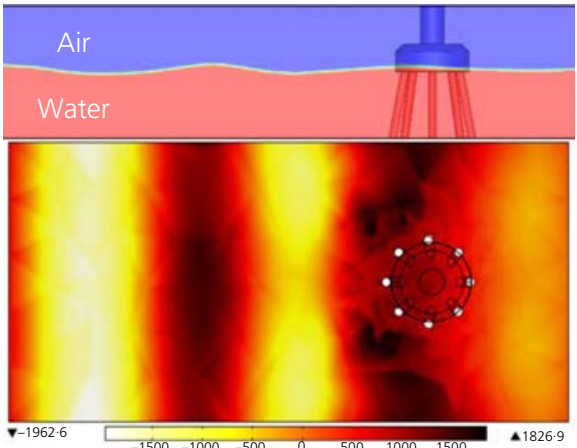

(b)

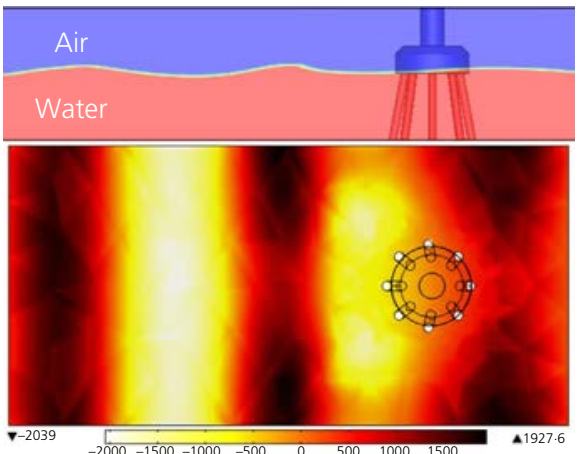

(e)

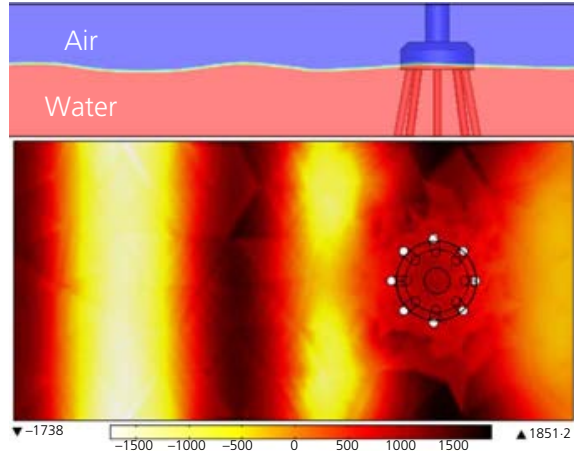

(c)

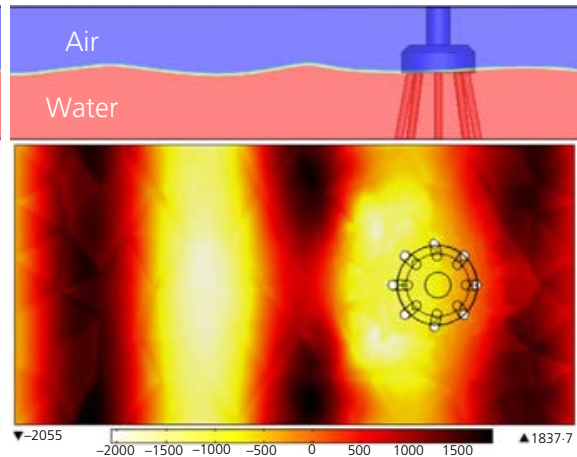

(f)

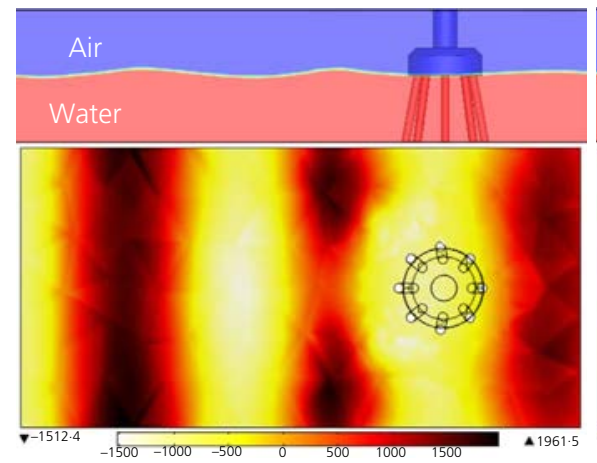

(g)

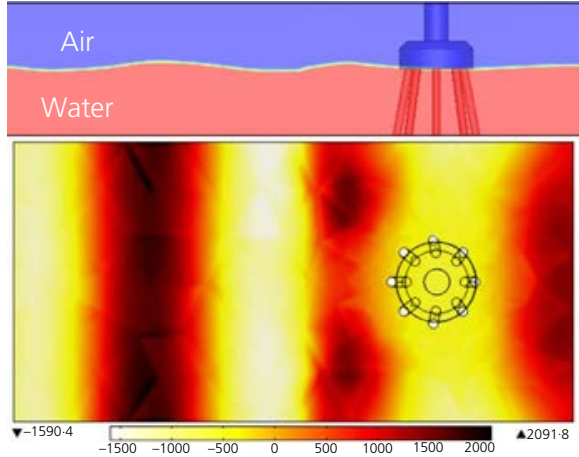

(h)

Figure 4. Distributions of wave profile and the wave-induced pore pressure around HRSF $1 \mathrm{~m}$ below the seabed surface at different times: $t / T=$ (a) $5 \frac{3}{8} ;$ (b) $5 \frac{1}{2} ;$ (c) $5 \frac{5}{8} ;$ (d) $5 \frac{3}{4} ;$ (e) $5 \frac{7}{8} ;$ (f) 6 ; (g) $6 \frac{1}{8} ;$ (h) $6 \frac{1}{4}$

and finally decreases slightly with depth again. On the other hand, the pore pressures in the seabed are negative from $t / T=5 \frac{7}{8}$ to $6 \frac{1}{4}$, and the distribution of pore pressure is approximately symmetrical with the previous half period.

\subsection{Effects of wave and soil characteristics}

In this section, the effects of several wave and soil characteristics on the wave-induced pore pressure around the foundation are further investigated. The wave height $(H)$, wave period $(T)$ and seabed degree of saturation $(S)$ that are determined to play key roles in the response are used in the parametric study.
The other wave and soil parameters used in numerical examples are presented in Table 2.

Figure 6 describes the distribution of wave-induced pore pressure at point $\mathrm{A}$ with three different wave heights. The wave period used here is $7 \cdot 76 \mathrm{~s}$, which is the average period of the DH-OWT. The incident wave with larger wave height accompanies more energy and therefore results in larger wave pressure on the seabed. Results in Figure 6 confirm that the magnitude of the wave-induced pore pressure increases as wave height increases. 
Soil response around Donghai

offshore wind turbine

foundation, China

Chang, Jeng, Zhang and Zhang

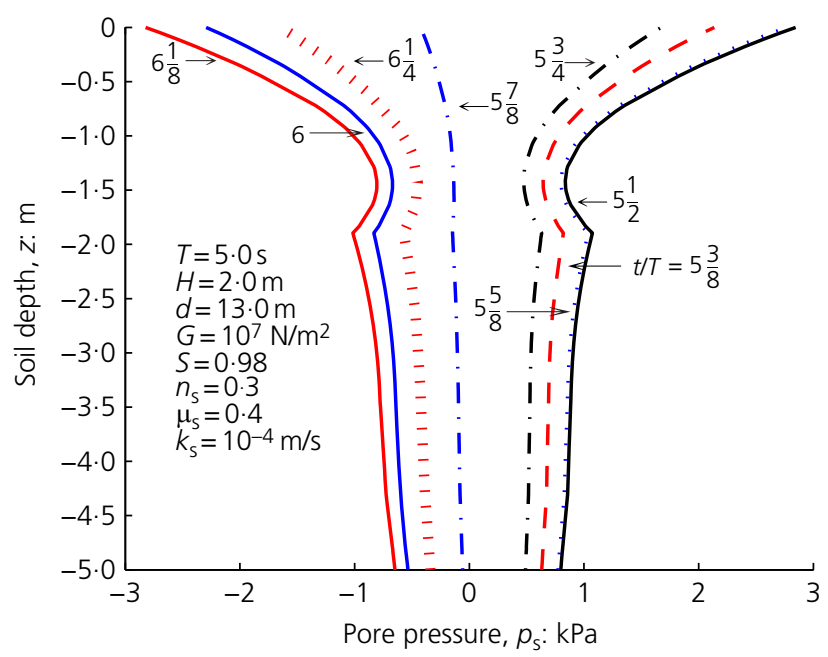

Figure 5. Vertical distributions of the wave-induced pore pressure $\left(p_{\mathrm{s}}\right)$ at point $\mathrm{A}$ from $t / T=5 \frac{3}{8}$ to $6 \frac{1}{4}$

Wave periods affect the wavelength together with water depth directly. In this example, three different wave periods, $T=5 \mathrm{~s}$, $7.76 \mathrm{~s}$ and $10 \mathrm{~s}$ are considered, and the corresponding wavelengths are $L=37.5 \mathrm{~m}, 75.3 \mathrm{~m}$ and $104.5 \mathrm{~m}$ respectively. Figure 7 presents the effects of wave period on the waveinduced pore pressure with wave height $H=2 \mathrm{~m}$. As represented in Figure 7, a longer wave period will cause a large magnitude of pore pressure in the seabed. A similar phenomenon can be seen in Figures 6 and 7: that is, the

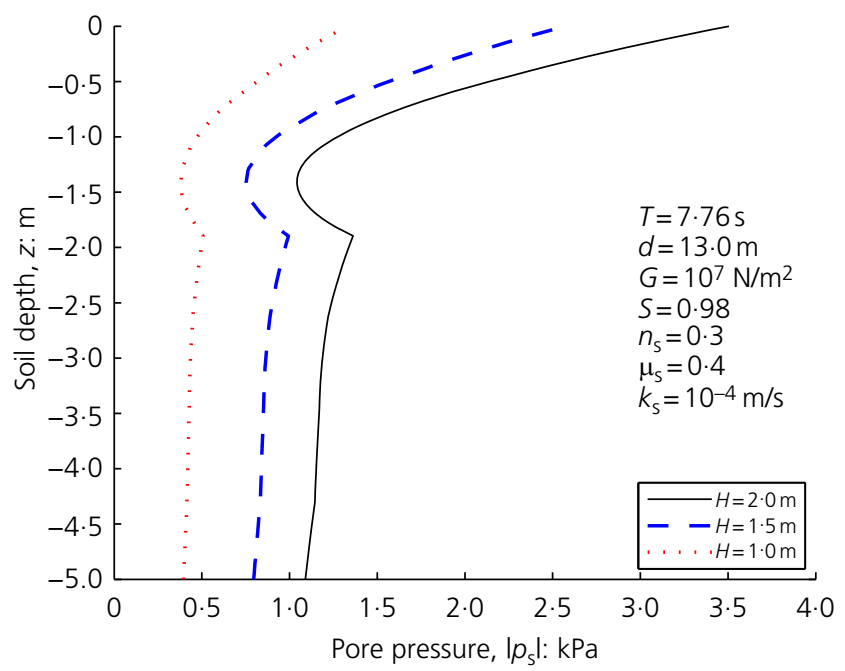

Figure 6. Vertical distributions of the wave-induced pore pressure $\left(\left|p_{s}\right|\right)$ plotted against soil depth $(z)$ for various wave heights at point $A$

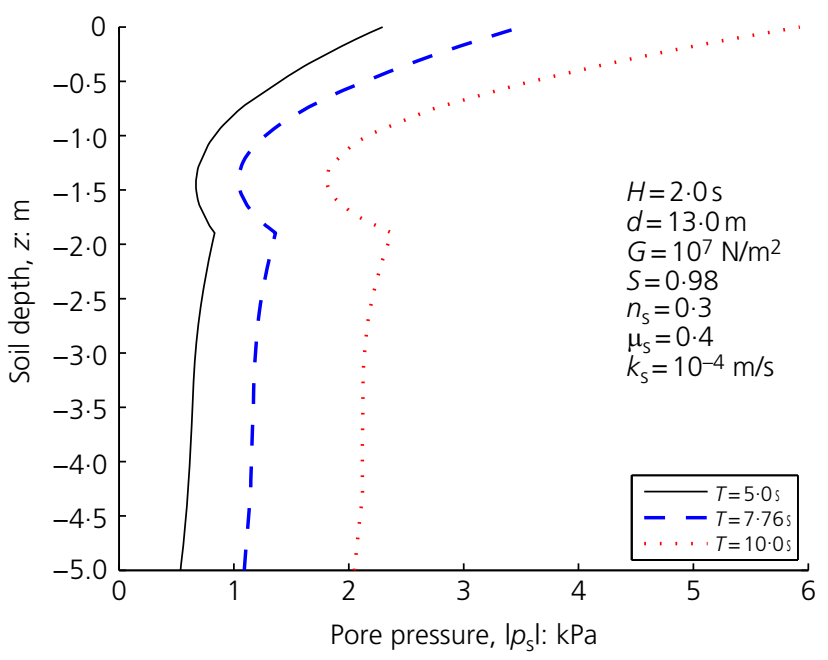

Figure 7. Vertical distributions of the wave-induced pore pressure $\left(\left|p_{s}\right|\right)$ plotted against soil depth $(z)$ for various wave periods at point $A$

profiles of pore pressure plotted against depth are approximately parallel curves, although different magnitudes of wave pressure are imposed on the seabed.

It is common to observe air/gas in marine sediments (Okusa, 1985). Hsu and Jeng (1994) reported that wave-induced soil response is affected significantly by the degree of saturation. Here, the wave-induced pore pressure for various degrees of saturation is further investigated. In the example, the degree of saturation is considered as $S=0.99,0.98$ and 0.97 . Figure 8 illustrates that pore pressure increases in the seabed as the degree of saturation increases; in other words, the dissipation rate of pore pressure increases as the degree of saturation decreases.

\subsection{Wave-induced liquefaction around HRSF}

Based on the proposed model, the wave-induced oscillatory soil response including pore pressures and effective stresses around the HRSF can be determined. Then, the wave-induced liquefaction around the HRSF can be further examined. An accurate prediction of the liquefaction zone will provide engineers with the evidence to improve the ground and optimise the design of a foundation or structure. Based on the liquefaction criterion proposed by Zen and Yamazaki (1990) and Jeng (1997, 2012), the liquefaction potential can be estimated by

13. $\sigma_{\mathrm{v} i}+\left(p_{\mathrm{b}}-p_{\mathrm{s}}\right) \leqslant 0$

where $\sigma_{\mathrm{v} i}$ is the initial stress due to dead loading (static water pressure and weight of the HRSF), which can be determined by 


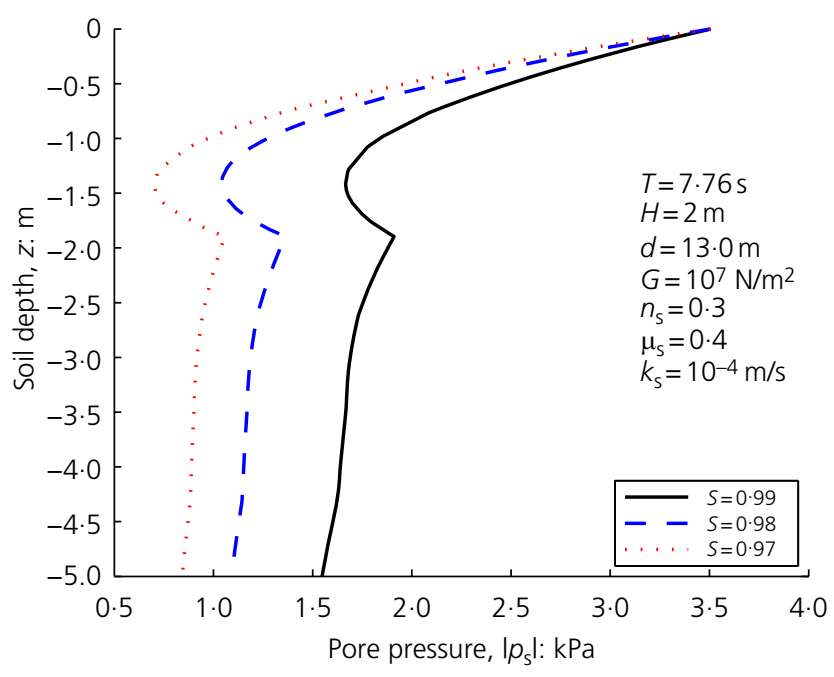

Figure 8. Vertical distributions of the wave-induced pore pressure $\left(\left|p_{s}\right|\right)$ plotted against soil depth $(z)$ for various degrees of saturation at point $A$

means of the poro-elastic model before the wave loading is applied. In Equation 13, $p_{\mathrm{b}}$ represents the hydrostatic pressure and $p_{\mathrm{s}}$ denotes the wave-induced pore pressure within the seabed.
Figure 9 illustrates the liquefied zone along the centre of the HRSF according to this criterion. As shown in the figure, the seabed near the piled foundation has the potential to be liquefied and the maximum liquefaction depth is up to $1 \mathrm{~m}$ with wave parameters measured from normal marine conditions. Then liquefaction depth will increase under an extreme offshore environment, which may further cause instability of the whole system.

\subsection{Comparison of seabed response to a GBF}

In this section, the wave-induced seabed response in the vicinity of a GBF is investigated, based on the present numerical model. The dimensions of the GBF adopted here are designed according to the optimum solution proposed by Henderson and Zaaijer (2002). The GBF diameter and height are $24 \mathrm{~m}$ and $2.4 \mathrm{~m}$ respectively. As shown in Figure 10, the vertical distributions of pore pressure for the two foundations are quite different with identical wave and seabed charcateristics. Differences exist in the wave field around GBF and HRSF because of their different shape. Furthermore, the different connection format between the structure and the seabed affects pore water accumulation and dissipation in the seabed. In practical work, engineers should pay attention to the different meachnics of wave-seabed-structure interactions and choose the optimised foundation style adapted to the local marine environment.

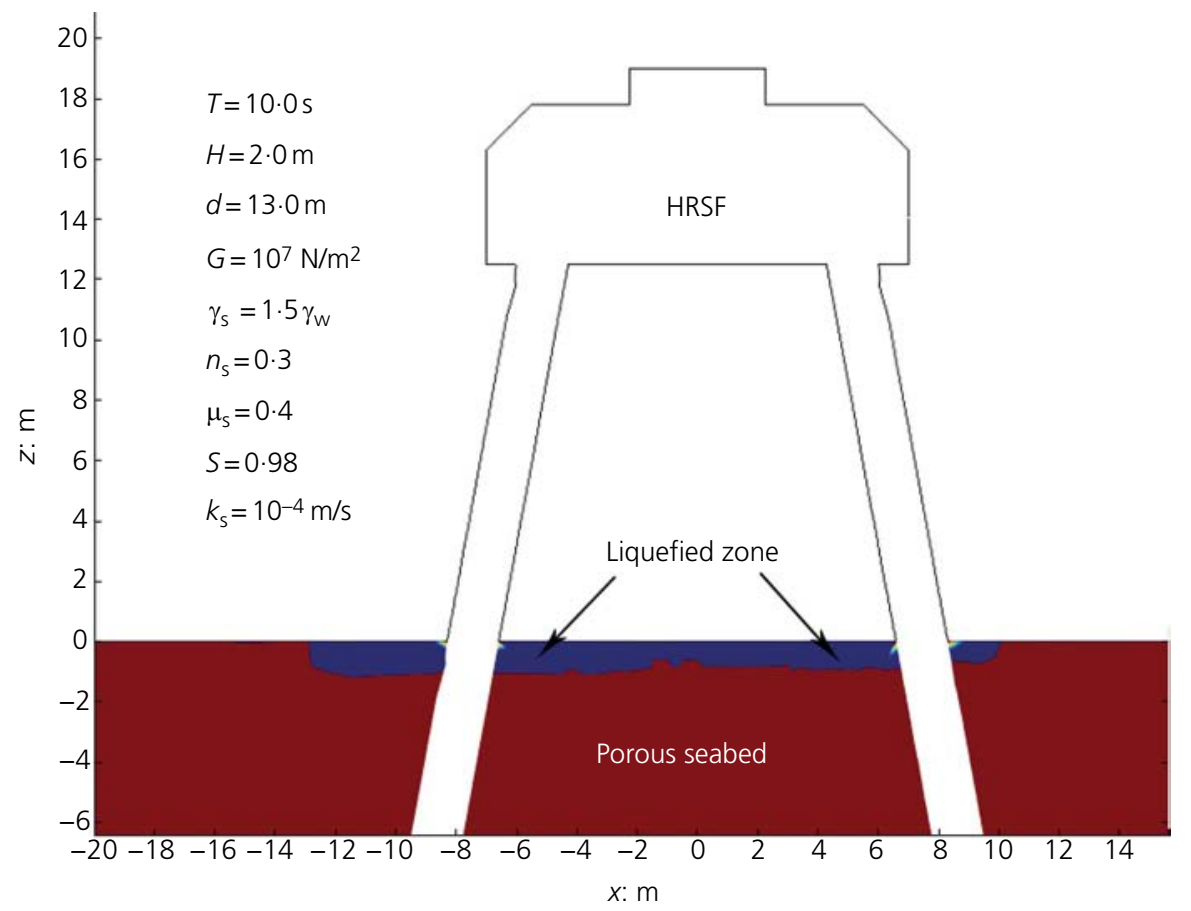

Figure 9. Wave-induced liquefaction around HRSF 
Soil response around Donghai

offshore wind turbine

foundation, China

Chang, Jeng, Zhang and Zhang

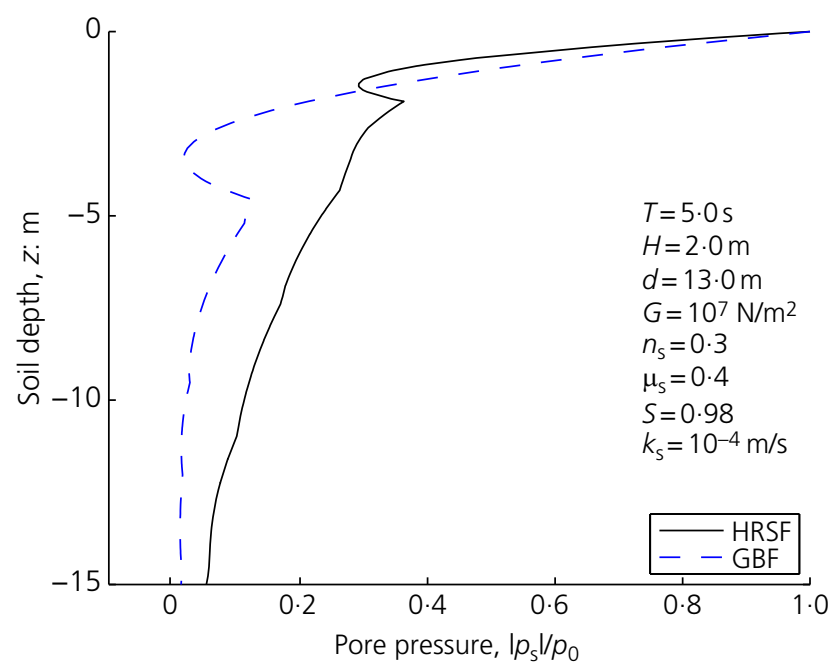

Figure 10. Comparison of vertical distributions of the waveinduced pore pressure $\left(\left|p_{s}\right| / p_{0}\right)$ plotted against soil depth $(z)$ between HRSF and GBF

\section{Conclusions}

In this paper, a detailed description of the $\mathrm{DH}-\mathrm{OWF}$ project is provided. Then, a 3D wave model with internal wave generation is presented, and a new seabed model developed within Comsol environments. These models are linked together to investigate the wave-induced pore pressure around the HRSF. Based on the numerical results presented, the following conclusions can be drawn.

(a) The existence of structure has a significant effect on the wave transformation and the distribution of waveinduced pore pressure. The magnitude of wave-induced pore pressure varies along the wave propagation periodically.

(b) Wave and soil parameters affect the wave-induced pore pressure response significantly. The magnitude of waveinduced pore pressure increases as wave height or wave period increases and the dissipation rate of pore pressure increases as the degree of saturation decreased.

(c) The liquefaction potential around the HRSF is estimated, based on the pore pressure distribution in the seabed, and transient liquefaction occurred due to wave propagation, which may further cause instability of the marine structure.

(d) The wave-induced seabed responses of the HRSF and GBF are different, even when the related wave and soil parameters are identical.

In this paper, because no laboratory experiments and field measurements for HRSFs at the DH-OWF are available in the literature, it is not possible to directly validate the present model for the HRSF. However, the numerical model presented in this paper was validated using previous experimental data for other types of marine structures (Jeng et al., 2013; Zhang et al., 2012a, 2012b). Data from physical modelling of such a structure are needed for future study.

\section{Acknowledgements}

The authors are grateful for the financial support from the EU Framework 7 Program, 'Mermaid', and SciChuan University State Key Laboratory of Hydraulics and Mountain River Engineering Open Fund scheme no. SKLH-OF-1005 (China), Hohai University State Key Laboratory of Hydrology-Water Resources and Hydraulic Engineering Open Fund scheme no. 2011491311 (China) and National Natural Science Foundation of China (grant no. 41176073), also Sino-UK high education exchange scheme (2013-2014) and Royal Society-NSFC joint project scheme (20132014, grant no. 51311130131).

\section{REFERENCES}

Barth TJ (1992) Aspects of unstructured grids and finite-volume solvers for the Euler and Navier-Stokes equations. In Special Course on Unstructured Grid Methods for Advection Dominated Flows. AGARD Report, vol. 1.

Biot MA (1941) General theory of three-dimensional consolidation. Journal of Applied Physics 12(2): 155-164.

Breton SP and Moe G (2009) Status, plans and technologies for offshore wind turbines in Europe and North America. Renewable Energy 34(3): 646-654.

Bussmann M, Kothe DB and Sicilian JM (2002) Modelling high density ratio incompressible interfacial flows. Proceedings of ASME 2002 Fluids Engineering Division Summer Meeting, Montreal, Canada.

Carter JMF (2007) North Hoyle offshore wind farm: design and build. Proceedings of the Institution of Civil Engineers - Energy 160(1): 21-29, http://dx.doi.org/10.1680/ener.2007.160.1.21.

Chen J (2011) Development of offshore wind power in China. Renewable and Sustainable Energy Reviews 15(9): 5013-5020.

Cuellar P (2011) Pile Foundations for Offshore Wind Turbines: Numerical and Experimental Investigations on The Behaviour under Short-Term and Long-Term Cyclic Loading. $\mathrm{PhD}$ thesis, Technical University of Berlin, Germany.

Doherty P and Gavin K (2012) Laterally loaded monopile design for offshore wind farms. Proceedings of the Institution of Civil Engineers - Energy 165(1): 7-17, http://dx.doi.org/10. 1680/ener.11.00003.

Hansen NM (2012). Interaction Between Seabed Soil and Offshore Wind Turbine Foundations. $\mathrm{PhD}$ thesis, Technical University of Denmark, Lyngby, Denmark.

Henderson AR and Zaaijer MB (2002) Hydrodynamic loading of compact structures and the effect on foundation design. Proceedings of Marine Renewable Energy Conference, Newcastle, UK. 
Hirt CW and Nichols BD (1981) Volume of fluid (vof) method for the dynamics of free boundaries. Journal of Computational Physics 39(1): 201-225.

Hsu JRC and Jeng DS (1994) Wave-induced soil response in an unsaturated anisotropic seabed of finite thickness. International Journal for Numerical and Analytical Methods in Geomechanics 18(11): 785-807.

Jeng DS (1997) Wave-induced seabed instability in front of a breakwater. Ocean Engineering 24(10): 887-917.

Jeng DS (2013) Porous Models for Wave-Seabed Interactions. Springer, Heidelberg, Germany.

Jeng DS, Ye JH, Zhang JS and Liu PLF (2013) An integrated model for the wave-induced seabed response around marine structures: Model verifications and applications. Coastal Engineering 72: 1-19.

Li XJ, Gao FP, Yang B and Zang J (2011) Wave-induced pore pressure responses and soil liquefaction around pile foundation. International Journal of Offshore and Polar Engineering 21(3): 233-239.

Lin P and Liu PLF (1999) Internal wave-maker for Navier-Stokes equations models. Journal of Waterway, Port, Coastal, and Ocean Engineering, ASCE 125(4): 207-415.

Ling $Y$ and Cai $X$ (2012) Exploitation and utilization of the wind power and its perspective in China. Renewable and Sustainable Energy Reviews 16(4): 2111-2117.

Liu YX (2012) Typhoon Haikui tests Sinovel Wind Group. China Equipment 9: 70-71.

Lu ZM (2010) Construction Progress Report of Shanghai Donghai Bridge Offshore Wind Farm. Shanghai Investigation, Design and Research Institute, Nanjing, China. See http://wenku.baidu.com/view/ 3e922f0f7cd184254b353583.html (accessed 22/03/2013).

Lundgren H, Lindhardt JHC and Romhild CJ (1989) Stability of breakwaters on porous foundation. Proceedings of 12 th
International Conference on Soil Mechanics and Foundation Engineering, Rio de Janeiro, Brazil, vol. 1, pp. 451-454.

Okusa S (1985) Wave-induced stress in unsaturated submarine sediments. Géotechnique 35(4): 517-532.

Rajgor G (2010). China gets serious on offshore wind. Renewable Energy Focus 11(5): 16-19.

Randolph MF (1981) Response of flexible piles to lateral loading. Géotechnique 31(2): 247-259.

Rider WJ and Kothe DB (1998) Reconstructing volume tracking. Journal of Computational Physics 141(2): 112-152.

Rodi W (1993) Turbulance Models and their Application in Hydraulics: A State-of-the-Art Review. Taylor and Francis, Delft, the Netherlands.

Wang ZX, Jiang CW, Ai Q and Wang CM (2009) The key technology of offshore wind farm and its new development in China. Renewable and Sustainable Energy Reviews 13(1): 216-222.

Yang Z and Jeremić B (2002) Numerical analysis of pile behaviour under lateral loads in layered elastic-plastic soils. International Journal for Numerical and Analytical Methods in Geomechanics 26(14): 1385-1406.

Zen K and Yamazaki H (1990) Mechanism of wave-induced liquefaction and densification in seabed. Soils and Foundations 30(4): 90-104.

Zhang J, Jeng DS, Liu PLF, Zhang C and Zhang Y (2012a) Response of a porous seabed to water waves over permeable submerged breakwaters with Bragg reflection. Ocean Engineering 43: 1-12.

Zhang Y, Zhang JS, Zhang H, Zhao H and Jeng DS (2012b) Threedimensional model for wave-induced dynamic soil response around breakwaters. Proceedings of the 22nd International Offshore and Polar Engineering (ISOPE) Conference, Rhodes, Greece, vol. 3, pp. 1349-1355.

\section{WHAT DO YOU THINK?}

To discuss this paper, please email up to 500 words to the editor at journals@ice.org.uk. Your contribution will be forwarded to the author(s) for a reply and, if considered appropriate by the editorial panel, will be published as discussion in a future issue of the journal.

Proceedings journals rely entirely on contributions sent in by civil engineering professionals, academics and students. Papers should be 2000-5000 words long (briefing papers should be 1000-2000 words long), with adequate illustrations and references. You can submit your paper online via www.icevirtuallibrary.com/content/journals, where you will also find detailed author guidelines. 